\title{
Characteristics of meteorological disasters and their impacts on the agricultural ecosystems in the northwest of China: a case study in Xinjiang
}

Meihua Wu ${ }^{1,2}$, Yaning Chen ${ }^{2}$, Huaijun Wang ${ }^{2}$ and Guili Sun ${ }^{3}$

\begin{abstract}
Background: In recent years, the meteorological extreme events have caused the direct economic losses and human mortality increased significantly. While there has been a paucity of information regarding trends in meteorological disasters in Xinjiang. Based on two extreme climate measurements, i.e., the Palmer Drought Severity Index (PDSI) and the agricultural disaster area, the influence of meteorological disasters on agriculture were analyzed during the period 1960-2010.

Results: (1) Temperature extremes exhibited patterns consistent with warming, with a large proportion of stations having statistically significant trends. The warming trends in the indices derived using daily minimum temperatures were greater than those obtained using maximum temperatures. Most of the precipitation indices exhibited increasing trends across the region, and the increased precipitation was due to the increase in both precipitation frequency and intensity. (2) The drought indices increased significantly in most regions of Xinjiang, and the seasonal PDSI exhibited significant correlations with the annual PDSI. For the entire geographical study area, two contrasting periods were evident in the PDSI between 1961 and 2010. Wet conditions dominated from 1987 to 2010, whereas persistent drought conditions occurred from 1960 to 1986. (3) Increased climate extremes resulted in increased agricultural disaster area. During warm summers, the droughts intensified; the corresponding snowmelt flood also became stronger. In addition, the sharply reduced effective irrigation area exacerbated the increased agricultural disaster area.
\end{abstract}

Conclusions: Climate change has affected the local agricultural oasis ecosystem and the yield and quality of crops in Xinjiang, leading to increased instability in agricultural production.

Keywords: Climate extremes; Palmer Drought Severity Index (PDSI); Agricultural disaster area; Xinjiang

\section{Background}

According to the World Meteorological Organization (WMO) estimate, losses caused by meteorological disasters have accounted for $85 \%$ of the total losses cause by natural disasters (Qiang et al. 2001; Qing 2008). In the last 20 years, the direct economic losses caused by meteorological extreme events have increased exponentially, and human mortality has also significantly increased (Loukas et al. 2010). China is one of the countries that has been most severely affected by the meteorological disasters around the world due to its complex terrain conditions, leading to

\footnotetext{
* Correspondence: chenyn@ms.xjb.ac.cn

${ }^{2}$ State Key Laboratory of Desert and Oasis Ecology, Xinjiang Institute of Ecology and Geography, Chinese Academy of Sciences (CAS), CAS, No. 818 South Beijing Road, Urumqi, Xinjiang 830011, China

Full list of author information is available at the end of the article
}

higher frequencies of extreme weather compared to other countries (Zhang et al. 1991). The crop disaster area caused by various meteorological disasters has been as high as $5 \times 10^{7}$ hectares every year, and the population affected by major meteorological disasters, such as typhoons, rainstorms, droughts, heat waves, and sand storms, has reached $4 \times 10^{8}$ (Qing 2008). During the period 1990-2006, the direct economic losses caused by meteorological disasters in China was $1859 \times 10^{8} \mathrm{RMB}$ per year, accounting for an average of for $2.8 \%$ of the annual GDP (Qing 2008).

Xinjiang has complex natural conditions that lead to a high frequency of various types of strong natural disasters (Ye and Chen 1996). Meteorological disasters and their derivative disasters have accounted for $83 \%$ of the total loss due to all natural disasters, and the number of deaths has accounted for $85 \%$ of the total (Liu 1995). These disasters 
have also exacerbated the deterioration of the ecological environment. Some new characteristics of these meteorological disasters and their derivative disasters have been found since the 1980s, including the increase in the types of events, increased frequency, and increased strength. According to incomplete statistics, the average annual loss was $1 \times 10^{7}-5 \times 10^{7}$ RMB, $1.4 \times 10^{8} \mathrm{RMB}$, and $20 \times 10^{8}-50 \times 10^{8} \mathrm{RMB}$ during the period 1950-1970, during the 1980s, and since the 1990s, respectively, accounting for $2 \sim 3.5 \%$ of the GDP in Xinjiang. Since the 1980s, the drought disaster area, inundated area, and various economic losses have increased significantly (Xu et al. 2008; Bai et al. 2012; Chen and Gao 2010; Chen et al. 2008).

Xinjiang is located in the arid region of northwestern China; its ecological environment is very fragile. The recovery period of the agricultural ecological system to disasters is relatively long. Analyzing the effects of meteorological disasters on the agricultural ecosystem in Xinjiang is very important for formulating corresponding disaster prevention countermeasures that can protect the ecological and environmental security. In addition, such an analysis is also favorable for formulating agricultural adaptation and mitigation measures in response to climate change and for maintaining social stability, which are very important for promoting the sustainable development of the national economy.

\section{Description of study area}

Xinjiang Province (Figure 1) is located in northwestern China. With an area of $16.61 \times 10^{8} \mathrm{~km}^{2}$, Xianjiang is the largest province in China. Xinjiang is a typical inland arid region. The Altai Mountains, Tian Mountains, and Kunlun Mountains extend from north to south in Xinjiang. The Junggar Basin in North Xinjiang and the Tarim Basin in

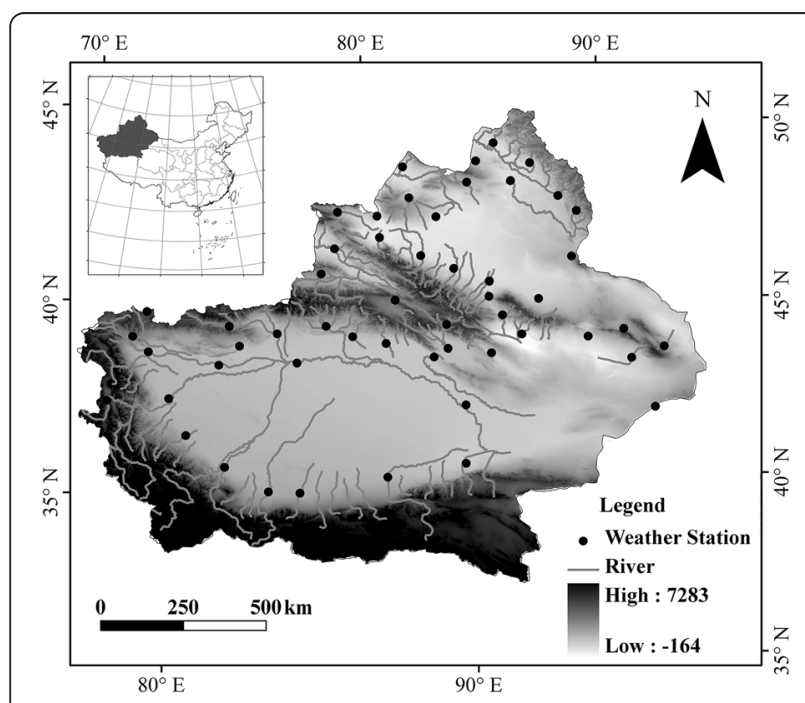

Figure 1 Study area and weather stations in Xinjiang Province.
South Xinjiang are located between these three mountains. Xinjiang is divided into southern and northern areas by its natural landscape, resulting in two mountain-basin systems with different hydrological and thermal conditions (Xu et al. 2004). The unique mountain-basin landscape is responsible for the frequent occurrence of natural disasters. Alpine areas are distributed widely in Xinjiang and possess numerous glaciers and permanent snow, which increase the frequency of outburst floods. The middle area experiences the highest precipitation in Xinjiang (Gao et al. 2002), and water erosion is very strong; therefore, floods and snowfalls result in most of the extreme events (Hong and Adler 2008). In the low mountain areas, active fault zones increase the occurrence of floods, landslides, and debris flows during rainstorms and seasonal snowmelt (Sun et al. 2014).

\section{Methods}

Daily data, include the maximum temperature, minimum temperature, precipitation, relative humidity, sunshine hours, air pressure, and wind speed (1 January 1960 to 28 February 2011) covering the Xinjiang region were provided by the National Climate Center (NCC) of the China Meteorological Administration (CMA). For this region, 53 stations passed the internal homogeneity check of the China National Meteorological Center (CNMC), including a moving $\mathrm{t}$ test (Peterson et al. 1998), standard normal homogeneity test (Alexandersson 1986), and departure accumulating method (Buishand 1982). Data were analyzed using the RclimDex package (software and documentation available for download from http://etccdi.pacificclimate.org/). Table 1 lists the indices used in this study. The regional average is the arithmetic mean of all stations in Xinjiang. The Xinjiang disaster area data were derived from the China Statistical Yearbook and Chinese agricultural statistics. The effective irrigation area and rural power data were also collected from the China Statistical Yearbook and Chinese agricultural statistics.

The PDSI is widely used in drought evaluation studies, which was developed by Palmer (1965) to measure the cumulative departure in atmospheric moisture supply and demand. The PDSI not only accounts for precipitation but also accounts for temperature, which has a large effect on evapotranspiration and soil moisture (Liu et al. 2012). The PDSI soil parameter that is used for bucket water balance is the available water content (AWC). The AWC was determined from the State Soil Geographic Database (STATSGO) for the top $100 \mathrm{~cm}$ of the soil profile. However, a common critique of the PDSI is that the behavior of the index at various locations is inconsistent, making spatial comparisons of the PDSI difficult. The SC-PDSI automatically calibrates the behavior at any location by replacing empirical constants with dynamically calculated values. 
Table 1 Definitions of 6 temperature indices and 5 precipitation indices used in this study; all of the indices are calculated using RClimDex

\begin{tabular}{lll}
\hline ID & Indicator name & Definitions \\
\hline Cold extremes & Cool nights & UNITS \\
TN10p & Coldest nights & Percentage of days when TN $<10$ th percentile \\
TNn & Cold spell duration indicator & Monthly minimum value of daily minimum temp \\
CSDI & Warm days & Annual count of days with at least 6 consecutive days \\
Warm extremes & Warmest days & when TN $<$ 10th percentile \\
TX90p & Warm spell duration indicator & Percentage of days when TX $>90$ th percentile \\
TXX & & Monthly maximum value of daily maximum temp \\
WSDI & & Annual count of days with at least 6 consecutive days \\
Variability extremes & when TX $>90$ th percentile \\
DTR & Diurnal temperature range &
\end{tabular}

More details regarding the PDSI and SC-PDSI can be found in the works of Liu et al. (2012) and Wells et al. (2004).

We used a nonparametric Kendall's tau-based slope estimator in this study (Sen 1968); statistical significance for the trends in extreme climate indices was determined using the Mann-Kendall test (Kendall 1975; Mann 1945). A trend was considered to be statistically significant if it was significant at the $5 \%$ level. The results of the $\mathrm{M}-\mathrm{K}$ test are substantially affected by serial correlation; therefore, we adopted the Yue and Pilon method, which uses the $\mathrm{R}$ package "ZYP" to remove lag-1 autocorrelations (Yue et al. 2002).

\section{Results and discussion}

\section{Characteristics of climate extremes}

Figure 2 depicts the spatial trends in the temperature indices for cold extreme (Figure 2a-b). For cold nights (TN10), 51 stations (96\%) had significant decreasing trends, with a regional trend of -1.89 days/decade. The temperature on the coldest nights (TNn) also exhibited a statistically significant increase at approximately $70 \%$ of the stations, and the regional trend was $0.7^{\circ} \mathrm{C} /$ decade. The cold spell duration indicator (CSDI) (not shown) decreased at a rate of -0.7 days/decade, while only $25 \%$ of the studied stations exhibited a significant change.

For the warm extremes (Figure 2c-d), $83 \%$ of the stations exhibited statistically significant trends for warm nights (TX90); the regional trend for TN90 was 1.25 days/ decade. The warmest days (TXx) also exhibited an increasing trend, while only $25 \%$ of the stations exhibited significant trends. The warm spell duration indicator (WSDI) (not shown) also increased, and the regional trend was 1.98 days/decade.

The regional seasonal trends in the DTR are shown in Figure 3. The regional trend in the annual DTR was $-0.28^{\circ} \mathrm{C} /$ decade. Winter exhibit the most significant decreasing trend, with a value of $-4^{\circ} \mathrm{C} /$ decade (Figure $3 \mathrm{~d}$ ). The decrease in the DTR was because the minimum temperature increased faster than the maximum temperature.

The spatial distribution of the trends in precipitation extremes is show in Figure 4. For R0.1 (Figure 4c), which represents the precipitation frequency, $40 \%$ of stations exhibited statistically significant changes. As for SDII (Figure 4b), positive trends were found at $83 \%$ of the stations; all stations were less coherent with positive/ negative changes. Heavy precipitation, which was represented by R10 (Figure 4a), was dominated by increasing trends. The R0.1 and CWD trends were 1.26 days/decade and 0.047 days/decade, respectively. The SDII trend was weaker. Therefore, the precipitation extremes exhibited significant changes in Xinjiang, specifically regarding the change in rainy days (R0.1), heavy precipitation events (R10) and the mean simple daily intensity index (SDII), indicating that the precipitation changes were reflected in both the frequency and intensity.

\section{Characteristics of climate extremes}

For the annual PDSI in Xinjiang (Figure 5a), 42 stations had significant increasing trends. Stations along the Tianshan Mountains and North Xinjiang exhibited more pronounced trends. The seasonal pattern of the PDSI was same as the annual PDSI (Figure $5 \mathrm{~b}-\mathrm{c}$ ), with correlation coefficients exceeding 0.94. A detailed analysis resulted in two contrasting periods (Figure 6). Wet conditions occurred during the period 1987-2010, while persistent drought conditions dominated during the period 1960-1987. The annual PDSI was negative before 1986 , and the mean was -1.5 , which indicated frequent drought events during these years. Thereafter, the PDSI 


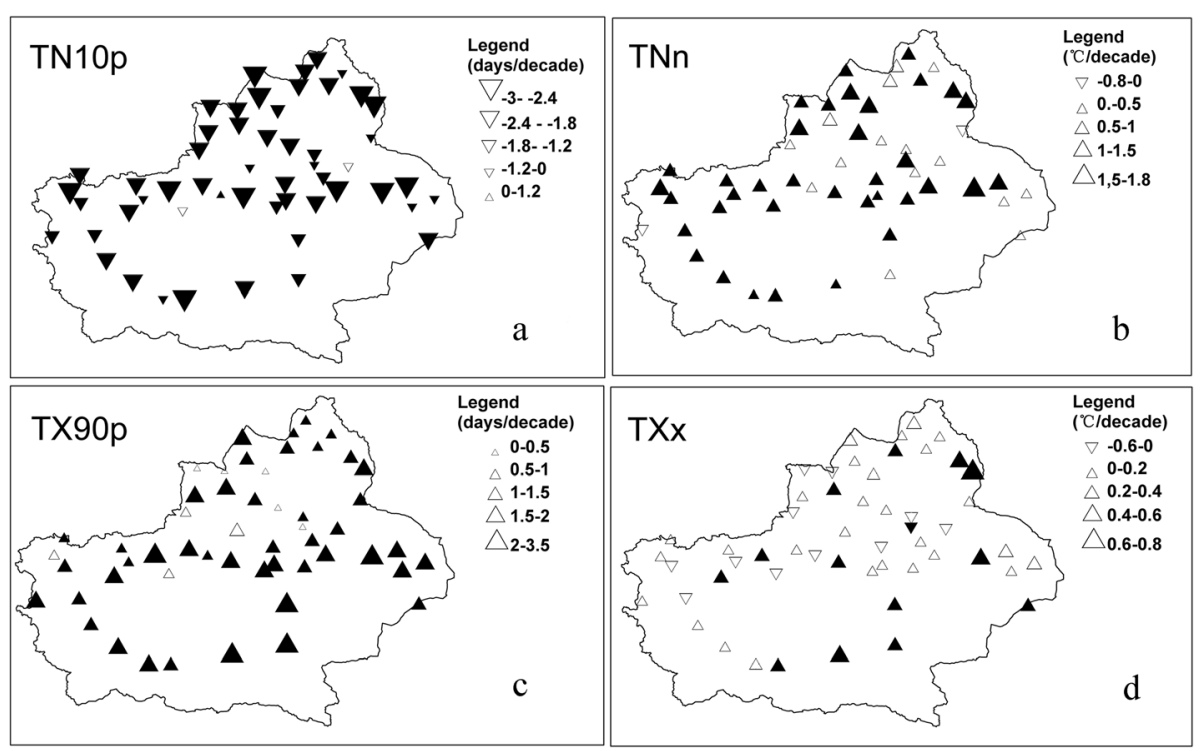

Figure 2 Spatial patterns of the changes in temperatures extremes per decade during the period 1960-2010 in Xinjiang. a: annual TN10p; b: annual TNn; c: annual TX90p; d: annual TXX. Positive/negative trends are shown as up/down triangles; the filled triangles are related to statistically significant trends (significant at the 0.05 level). The triangle sizes are proportional to the magnitude of the trends.

changed to -0.5 ; therefore, the PDSI also exhibited a step-wise change around 1986. These results were in accordance with climate (temperature and precipitation) change (Shi et al. 2007). Moreover, the PDSI exhibited decreasing trends after 2005, indicating the apparent increase in drought severity.
Influence of meteorological disasters on Agriculture

Agriculture is the most sensitive sector to climate change. Affected by climate change, the agricultural growth process is constantly changing. Climate change has a direct effect on agricultural ecosystems, often lead to increased instability and volatility in agricultural production. The crop
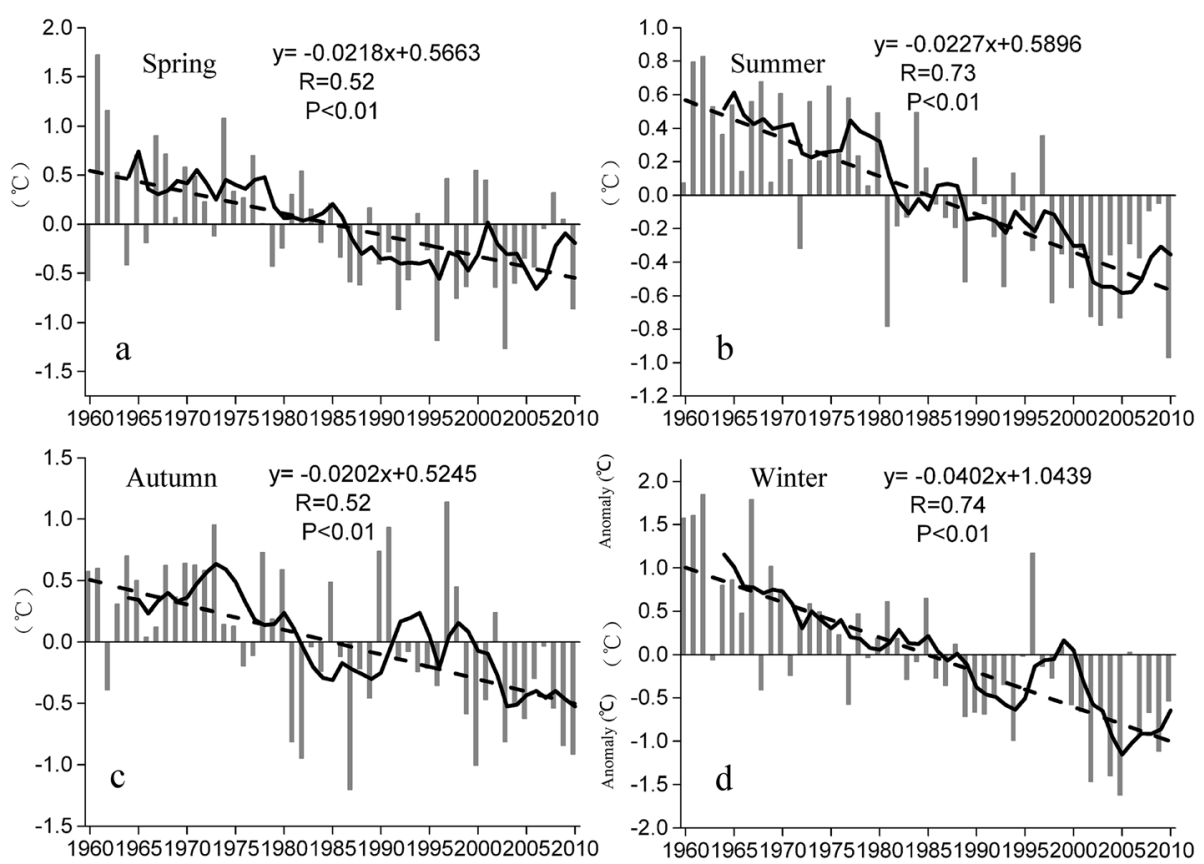

Figure 3 Regional trends in the DTR (the column is the annual anomaly series; the solid line is the 5-year-smoothed average; and the dashed line is the linear regression). $\mathbf{a}$ : spring DTR; $\mathbf{b}$ : summer DTR; $\mathbf{c}$ : autumn DTR; $\mathbf{d}$ : winter DTR. 

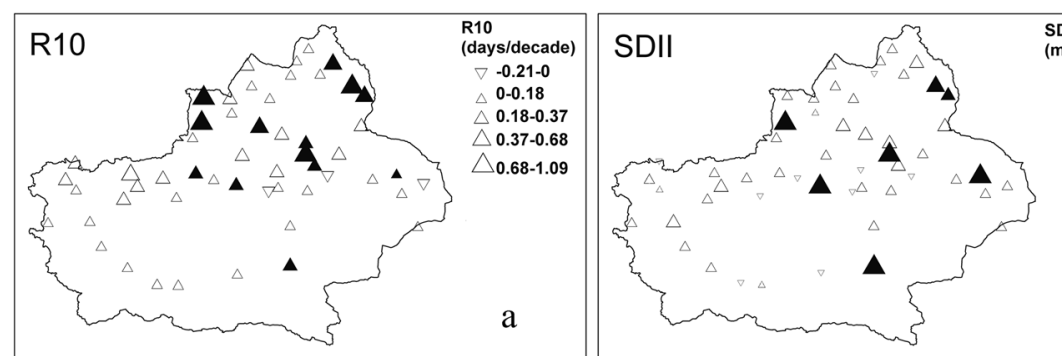

$(\mathrm{mm} /$ day $) /$ decade

$-0.3-0$
$0-0.1$

$0.1-0.2$

$0.2-0.3$

$\triangle 0.3-0.4$
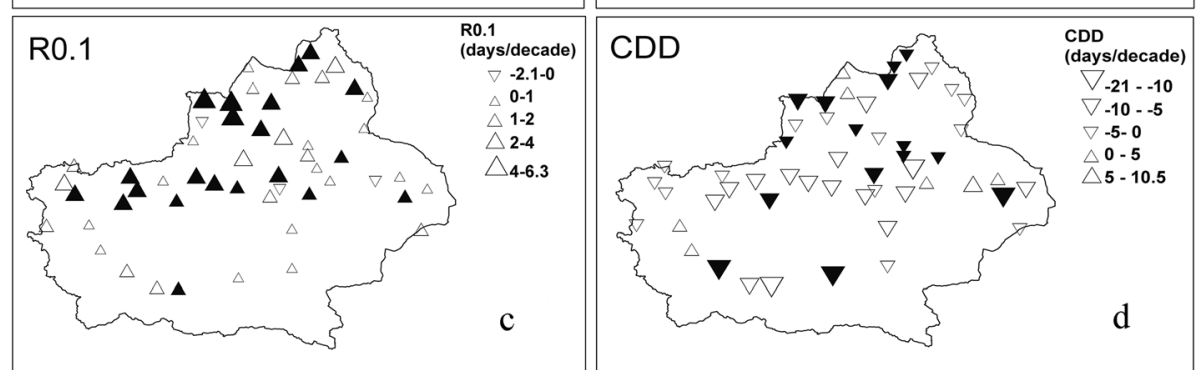

Figure 4 Spatial distribution of the trends and trend magnitudes for precipitation extremes. $\mathbf{a}$ : annual R10; b: annual SDII; c: annual R0.1; d: annual CDD. Positive/negative trends are shown as up/down triangles; the filled triangles are related to statistically significant trends (significant at the 0.05 level). The triangle sizes are proportional to the magnitude of the trends.

acreage in Xinjiang increased at a rate of $6.21 \times 10^{7} \mathrm{mu} /$ year; the changes can be divided into several distinct phases. The area increased significantly during the periods 1950-1970 and 1995-2012, while the area remained stable during the period 1970-1995 (Figure 7a). The grain crop area decreased substantially after 1970 before reversing in 2008. The area of planted wheat and corn changed in a similar manner to that of the crop acreage, experiencing a progression of increases, decreases, and ultimately increase again. Because of the increased yield per mu, the wheat and

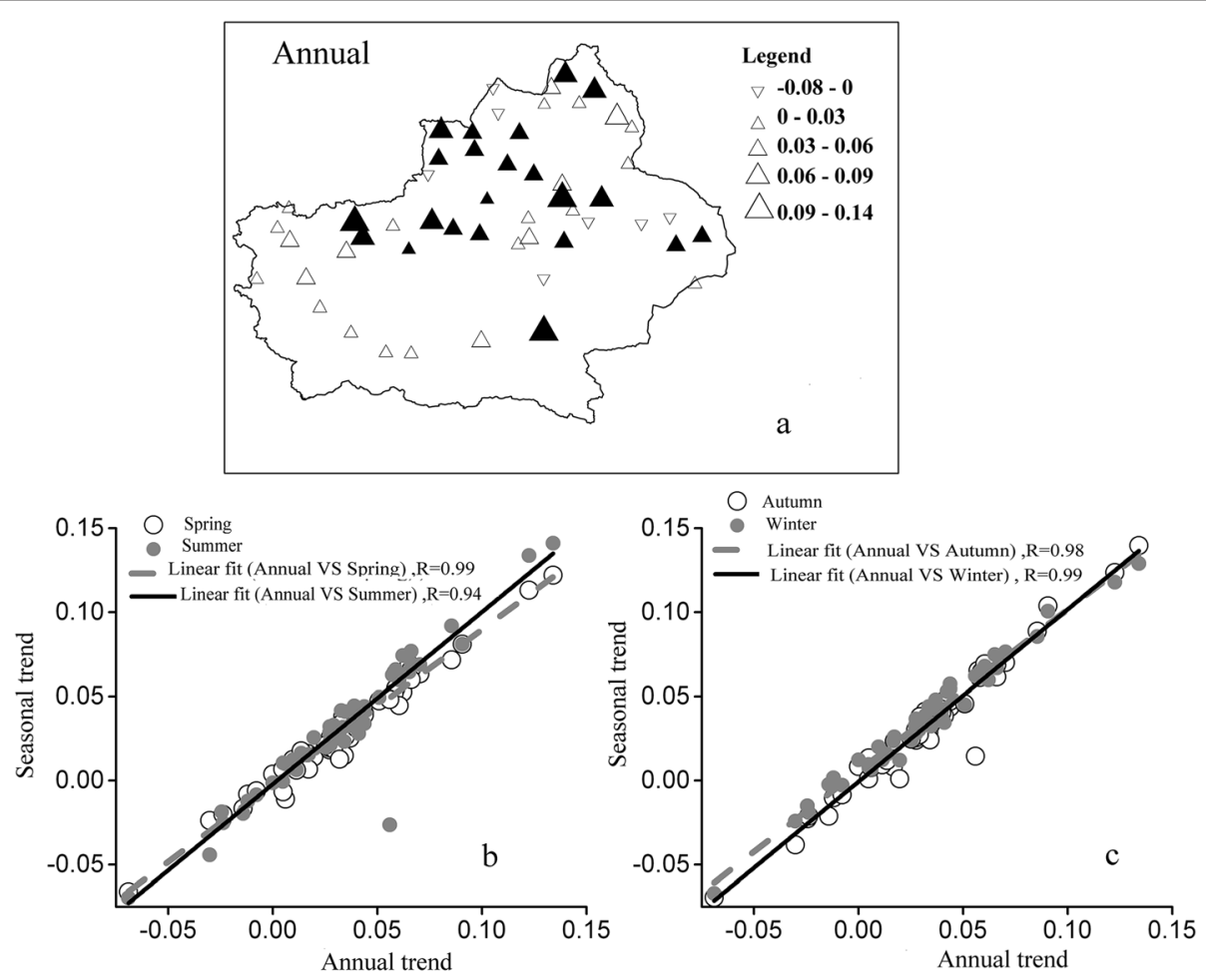

Figure 5 Spatial pattern of decadal trends and spatial characteristic for the seasonal PDIS and the annual PDSI in Xinjiang. a: Spatial trends of annual PDSI and $\mathbf{b}$, c: correlations between the seasonal and annual series. 


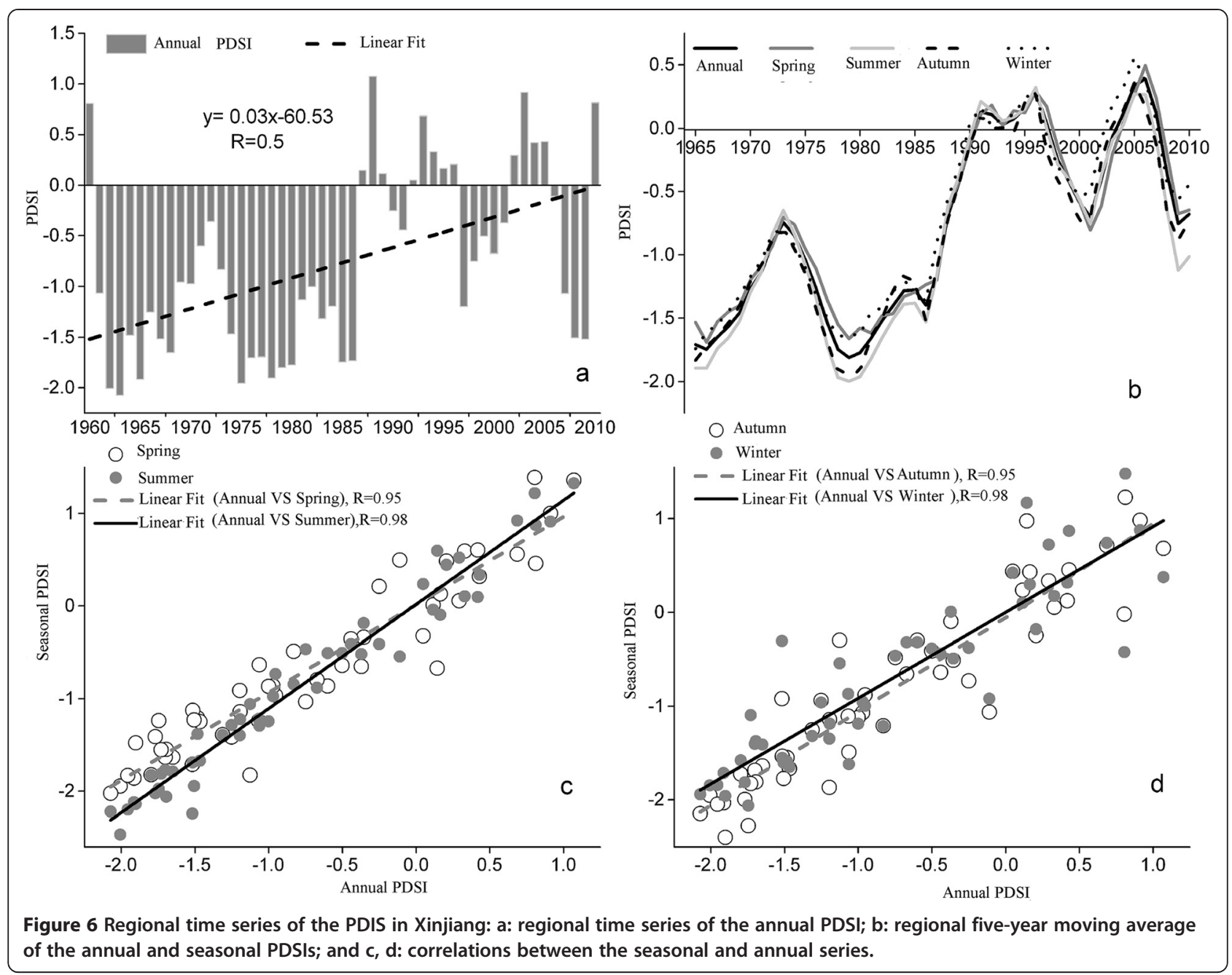

corn yields increased substantially (Figure 7c-d). After 2000, the yield/mu maintained a relatively constant level; an increasing trend was not well defined. Therefore, when agriculture developed to a certain level, it was challenging to achieve increasing yields through improved irrigation measures and increased input in the agriculture sector. The economic crop area exhibited a continuous increasing trend. Moreover, in 1998, the planted area exceeded the grain crop area. In the case of cotton, the area, yield and yield per mu increased after 1980 (Figure 7b). Based on the above analysis, the crop acreage increased in Xinjiang primarily due to increased economic crops.

The statistical results show that the devastated farmland resulting from meteorological disasters increased (either based on the disaster area or the disaster ratio), especially after 1970 (Figure 8a). Flood disaster areas (Figure 8b) were primarily concentrated after 1987, which confirms that the climate in Xinjiang shifted from warm and dry to warm and wet around 1987. Droughts and storms occurred primarily after 1970 (Figure 8c-d). The increasing trend in the storm disaster area was very well defined. For example, the storm disaster area was 210000 acres in the 1960's and increased to 2430000 acres in the 2000's. The proportion affected by low temperatures increased after 1995, especially in 2009, which is when the proportion reached $20 \%$ (Figure 8e). This finding indicates that the climate warmed, which simultaneously exacerbated the climate instability and resulted in extreme low temperature events during some periods.

The correlation coefficients between the trend in regional climate extremes and the disaster area are shown in Table 2. The statistical data representing the affected areas may be not comprehensive before 1986; therefore, we also discuss data since 1986 via a separate analysis (Table 3). The disaster area exhibited a significant correlation with extreme temperature drought indices, especially the TN10p and TX90p, indicating that the disaster area was primarily controlled by temperature extremes. When the summertime temperature was warm, the corresponding affected farmland area increased. The reasons for floods/droughts are complex and are closely related to the weather, geographical conditions, water conservancy facilities, soil structure, 


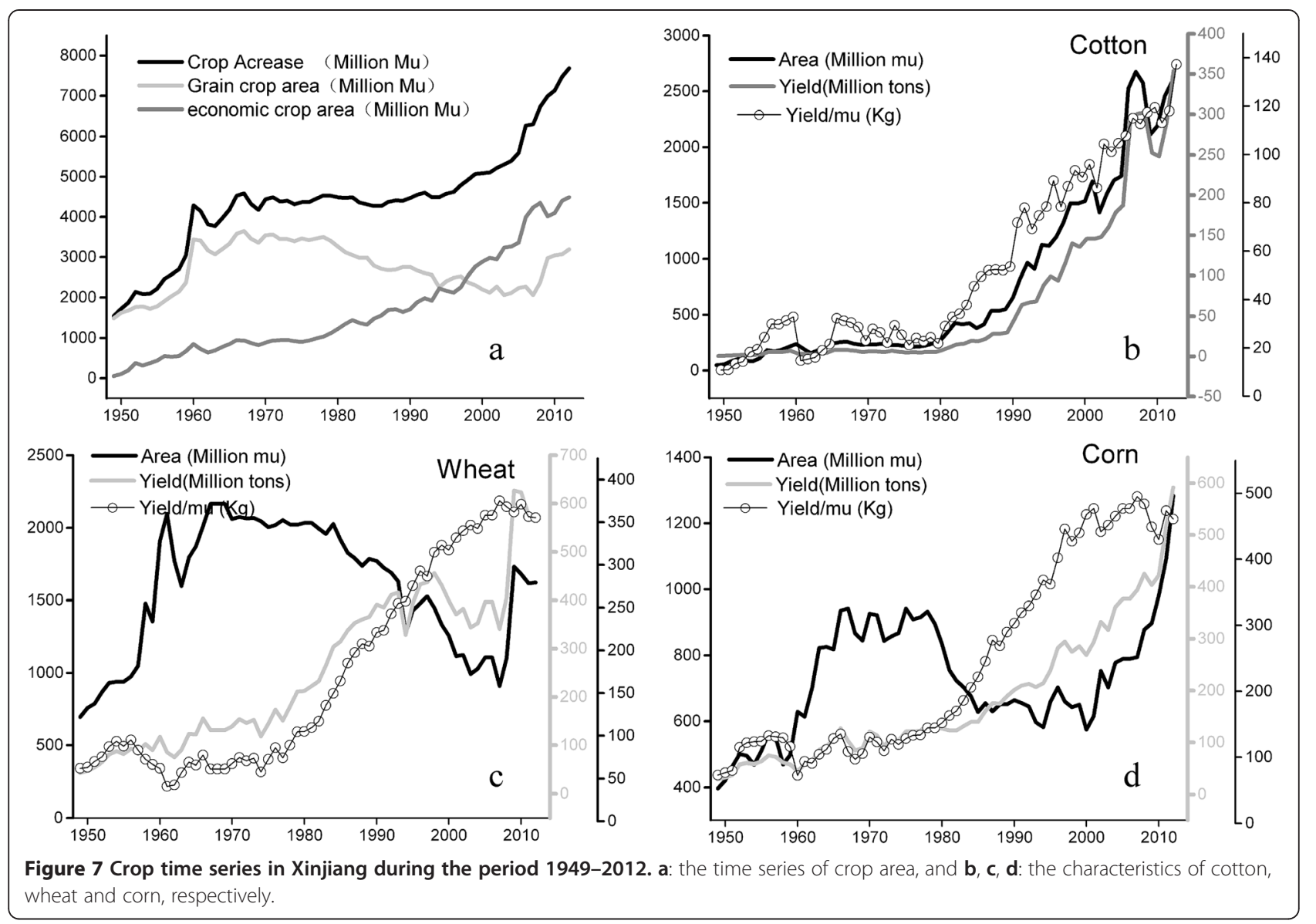

and primarily precipitation extremes. Regardless, changes in the frequency (R0.1), intensity (SDII), amplitude (R10) and duration (CWD) of precipitation events will increase the flood disaster area (Table 2). Drought events exhibited a negative correlation with extreme precipitation events, i.e., when the precipitation intensity and frequency increased, the number of drought events decreased. The enhanced warm temperature extremes (WSDI) resulted in intensified drought. For example, high temperatures in winter increase soil moisture evaporation, affect the safe overwintering of crops, decrease soil entropy, and increase the possibility of soil drought. The PDSI exhibited a negative correlation with drought events, especially after 1986 (Table 3), which is when the correlation was significant. This result indicates that the PDSI partially reflects the drought extent, which can be used to assess drought events in Xinjiang. The storm disaster area was related to the temperature index, indicating that extreme temperatures play a vital role in the formation of strong convective weather. Moreover, the low temperature disaster area was also associated with the extreme temperature index; however, the correlation was found to be positive when compared with warm temperature extremes, which is inconsistent with the actual relationship. This result may be related to climate change variability. For example, within a single year, extremely warm events can occur in combination extremely cold events. The cold events lead to rapid increases in the disaster area. Xinjiang has a typical irrigation agriculture; the shortage of water resources is very serious due to the sharp increase in irrigated area. Based on the exponential growth in rural consumption (Figure 9), we can speculate that the annual extracted groundwater volume increased. Moreover, the effective irrigation area decreased substantially in recent years, which has also resulted in an increase in the disaster area, especially due to the expansion of drought-affected areas.

\section{Conclusions}

The characteristics of Xinjiang meteorological disasters were analyzed using extreme indices and the PDSI. Combined with data for the farmland disaster area, we also analyzed the influence of meteorological disasters on the agricultural and ecological systems. The primary conclusions of this study are as follows:

1) In Xinjiang, the climate became warmer and wetter, with cold extremes decreasing and warm extremes increasing. Moreover, climate extremes derived from 


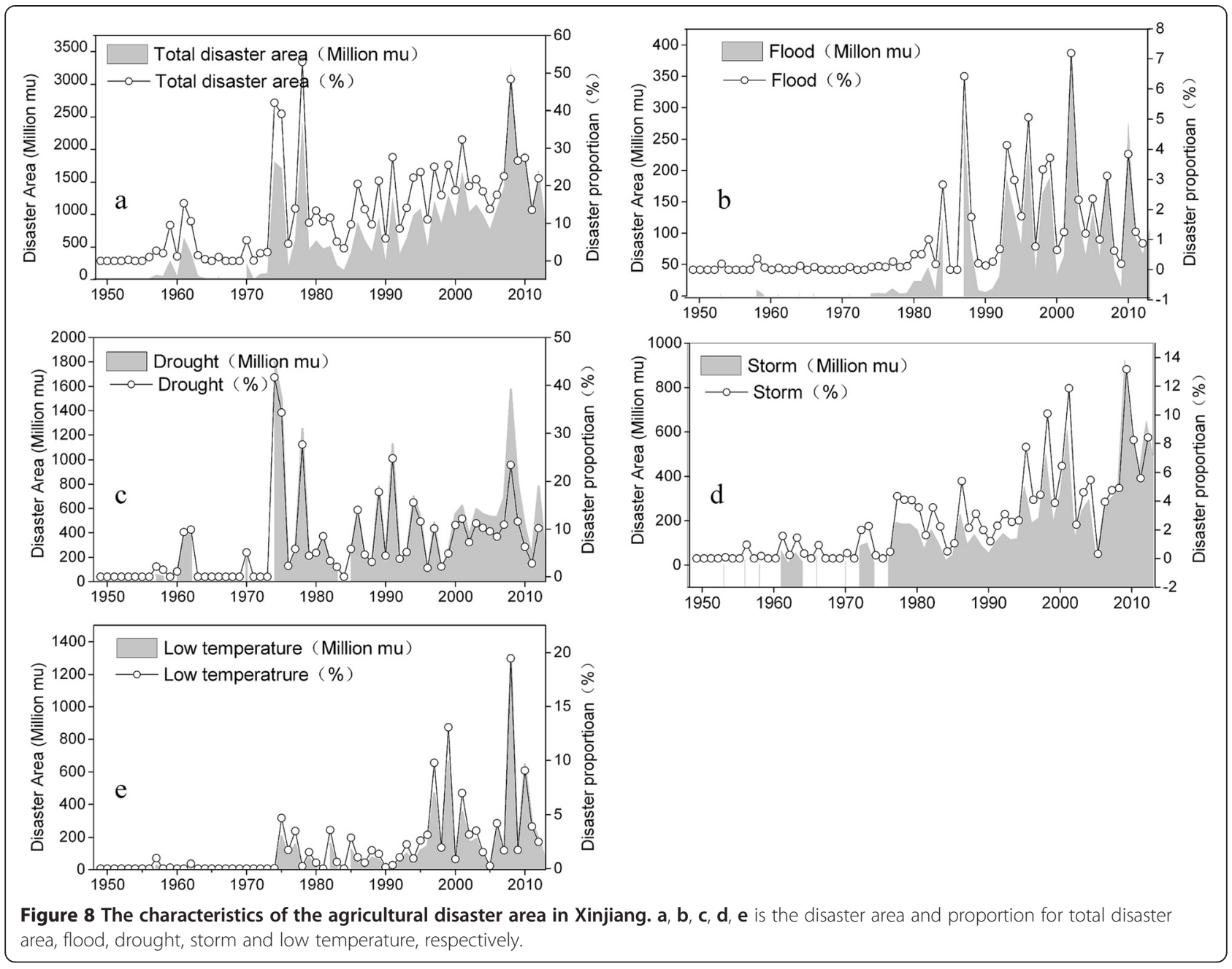

Table 2 Correlations between climate extremes and the agricultural disaster area in Xinjiang

\begin{tabular}{|c|c|c|c|c|c|c|c|c|c|c|}
\hline & \multicolumn{5}{|c|}{ Area (Million mu) } & \multicolumn{5}{|c|}{ Proportion (\%) } \\
\hline & Total & Flood & Drought & Storm & Low temperature & Total & Flood & Drought & Storm & Low temperature \\
\hline$\overline{C W D}$ & .057 & $.581^{* *}$ & -.119 & .199 & .123 & -.018 & $.551^{* *}$ & -.175 & .192 & .083 \\
\hline SDII & -.067 & $.572^{* *}$ & -.223 & .081 & -.011 & -.112 & $.546^{* *}$ & -.231 & .049 & -.033 \\
\hline R0.1 & .043 & $.547^{* *}$ & -.105 & .249 & .068 & -.024 & $.549^{* *}$ & -.179 & .261 & .008 \\
\hline R10 & .051 & $.738^{* *}$ & -.207 & $.280^{*}$ & .148 & -.038 & $.703^{* *}$ & -.267 & $.277^{*}$ & .113 \\
\hline RX1day & .057 & $.656^{* *}$ & -.110 & .176 & .040 & .014 & $.621^{* *}$ & -.147 & .182 & .026 \\
\hline CSDI & .005 & -.138 & .158 & $-.349^{*}$ & -.063 & .046 & -.114 & .195 & $-.390^{* *}$ & -.091 \\
\hline TN10p & $-.651^{* *}$ & $-.532^{* *}$ & $-.356^{*}$ & $-.662^{* *}$ & $-.589^{* *}$ & $-.518^{* *}$ & $-.460^{* *}$ & -.212 & $-.627^{* *}$ & $-.571^{* *}$ \\
\hline $\mathrm{TNn}$ & .101 & .207 & -.074 & $.358^{*}$ & .090 & .082 & .196 & -.066 & $.408^{* *}$ & .164 \\
\hline DTR & $-.380^{* *}$ & $-.628^{* *}$ & -.159 & $-.477^{* *}$ & $-.311^{*}$ & $-.299^{*}$ & $-.607^{* *}$ & -.073 & $-.484^{* *}$ & $-.291^{*}$ \\
\hline TX90p & $.533^{* *}$ & $.397^{* *}$ & .276 & $.492^{* *}$ & $.534^{* *}$ & $.441^{* *}$ & $.335^{*}$ & .168 & $.482^{* *}$ & $.542^{* *}$ \\
\hline$T X X$ & $.329^{*}$ & -.070 & .277 & .209 & $.377^{* *}$ & $.296^{*}$ & -.106 & .222 & .205 & $.376^{* *}$ \\
\hline WSDI & $.470^{* *}$ & $.375^{* *}$ & .236 & $.412^{* *}$ & $.551^{* *}$ & $.368^{* *}$ & $.317^{*}$ & .116 & $.419^{* *}$ & $.553^{* *}$ \\
\hline PDSI & .046 & $.565^{* *}$ & -.088 & .147 & .060 & .013 & $.561^{* *}$ & -.103 & .176 & .068 \\
\hline
\end{tabular}

*Indicates significance at $<0.05$ and ${ }^{*}$ indicates significance at $<0.01$. 
Table 3 Correlations between climate extremes and the agricultural disaster area in Xinjiang after 1986

\begin{tabular}{|c|c|c|c|c|c|c|c|c|c|c|}
\hline & \multicolumn{5}{|c|}{ Area (Million mu) } & \multicolumn{5}{|c|}{ Proportion (\%) } \\
\hline & Total & Flood & Drought & Storm & Low temperature & Total & Flood & Drought & Storm & Low temperature \\
\hline$\overline{C W D}$ & -.289 & $.490^{*}$ & -.363 & -.242 & -.146 & -.363 & $.449^{*}$ & -.339 & -.270 & -.202 \\
\hline SDII & -.319 & $.635^{* *}$ & $-.527^{* *}$ & -.162 & -.186 & $-.408^{*}$ & $.604^{* *}$ & $-.566^{* *}$ & -.163 & -.197 \\
\hline R0.1 & -.299 & $.438^{*}$ & $-.423^{*}$ & -.043 & -.248 & -.403 & $.438^{*}$ & $-.448^{*}$ & -.069 & -.313 \\
\hline R10 & -.211 & $.710^{* *}$ & $-.542^{* *}$ & .003 & -.062 & -.327 & $.654^{* *}$ & $-.612^{* *}$ & -.017 & -.091 \\
\hline RX1day & -.382 & $.610^{* *}$ & $-.531^{* *}$ & -.213 & -.279 & $-.464^{*}$ & $.568^{* *}$ & $-.545^{* *}$ & -.224 & -.287 \\
\hline CSDI & .316 & .208 & .213 & -.050 & $.404^{*}$ & .283 & .268 & .115 & -.079 & .346 \\
\hline TN10p & $-.672^{* *}$ & -.177 & -.401 & $-.441^{*}$ & $-.528^{* *}$ & $-.536^{* *}$ & -.029 & -.184 & -.321 & $-.474^{*}$ \\
\hline TNn & -.310 & -.206 & -.287 & .019 & -.281 & -.303 & -.211 & -.230 & .010 & -.210 \\
\hline DTR & -.030 & $-.410^{*}$ & .102 & -.090 & .018 & .104 & -.348 & .198 & -.014 & .098 \\
\hline TX90p & $.544^{* *}$ & .186 & .282 & .295 & $.510^{*}$ & $.502^{*}$ & .091 & .132 & .253 & $.517^{* *}$ \\
\hline$T X x$ & .343 & -.174 & .193 & .163 & $.436^{*}$ & .288 & -.265 & .085 & .157 & $.427^{*}$ \\
\hline WSDI & $.567^{* *}$ & .120 & $.406^{*}$ & .177 & $.517^{* *}$ & $.564^{* *}$ & .026 & .293 & .158 & $.520^{* *}$ \\
\hline PDSI & $-.521^{* *}$ & .352 & $-.461^{*}$ & $-.420^{*}$ & -.366 & $-.513^{*}$ & .364 & -.351 & -.392 & -.374 \\
\hline
\end{tabular}

*Indicates significance at $<0.05$ and ${ }^{* *}$ indicates significance at $<0.01$.

daily minimum temperatures were more numerous that the extremes derived from daily maximum temperatures, which was found to be consistent with the significantly decreased DTR. Precipitation extremes also increased due to the increase in both precipitation frequency and intensity. Frequent and long droughts occurred from 1960 to 1986, although wet climates prevailed from 1987 to 2010 . However, after 2003, droughts became more prolific, which was reflected in a drastic decrease in the PDSI.

2) Extreme temperatures had a significant effect on the farmland disaster area in Xinjiang. For example, summertime warm events resulted in an increase in the affected farmland area. Floods were primarily related to extreme precipitation, while the storm disaster area and the low temperature disaster area were the result of changes in temperature extremes. Climate change can also affect the agricultural ecosystem and the oasis crop yield and quality in various ways, leading to increased instability in agricultural production. This study showed that the strengthening of climate warming and evaporation capacity not only increased the soil moisture but also decrease the soil entropy, increased spring drought, accelerated the production of organic matter due to soil microbial decomposition, resulting in the decline in soil fertility and decreased yields. To maintain soil fertility, the fertilization amount must also increase. Although the climate warming can improve grain yields in some regions, climate warming can cause the agriculture water consumption per unit to increase, which also increases production costs. Especially in winter, an increase in extreme minimum temperatures will reduce overwinter human mortality, expand agricultural pest regions, increase the pesticide control difficulty and application amount.
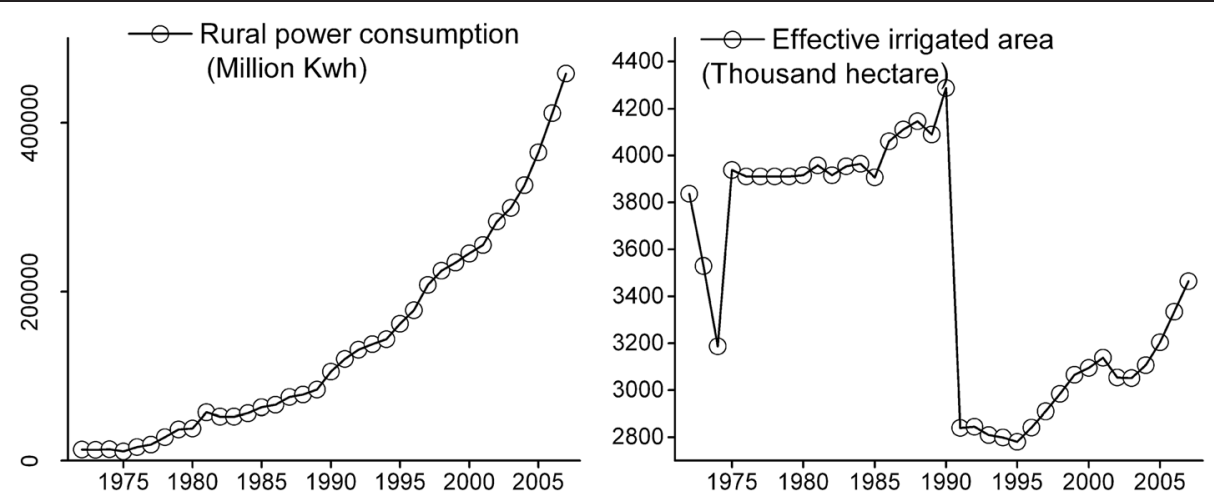

Figure 9 Changes in rural electricity consumption and the effective irrigation area in Xinjiang. 


\section{Competing interests}

The authors declare that they have no competing interests.

\section{Authors' contributions}

MW carried out data analysis and write the manuscript. YC provided suggestions and advices to the study and checked the manuscript. HW and GS provided unpublished data and added some useful comments to improve the paper. All authors read and approved the final manuscript.

\section{Acknowledgements}

The research is supported the Natural Sciences Foundation of China (Grant No.41361093). The authors thank the National Climate Central, China Meteorological Administration, for providing the meteorological data for this study.

\section{Author details}

${ }^{1}$ Key Laboratory of Oasis Ecology, School of Resource and Environmental Sciences, Xinjiang University, Urumqi, Xinjiang 830046, China. ${ }^{2}$ State Key Laboratory of Desert and Oasis Ecology, Xinjiang Institute of Ecology and Geography, Chinese Academy of Sciences (CAS), CAS, No. 818 South Beijing Road, Urumqi, Xinjiang 830011, China. ${ }^{3}$ Forestry and Horticulture Department, Xinjiang Agriculture University, Urumai, Xinjiang 830052, China.

Received: 4 December 2014 Accepted: 17 January 2015

Published online: 12 February 2015

\section{References}

Alexandersson H (1986) A homogeneity test applied to precipitation data. J Climatol 6(6):661-675

Bai YG, Musha RZ, Lei XY, Zhang JH (2012) Analysis on characteristics and affecting factor of drought disaster of Xinjiang. Yellow River 34(07):61-63 (in Chinese with English abstract)

Buishand TA (1982) Some methods for testing the homogeneity of rainfall records. J Hydrol 58(1-2):11-27

Chen YF, Gao G (2010) An analysis to losses caused by meteorological disasters in China during 1989-2008. Meteorological Mon 36(02):76-80 (in Chinese with English abstract)

Chen XJ, Liu XF, Yang XH (2008) Current position of natural disasters in Xinjiang and their control countermeasures. Territory Nat Resour Stud 3(030):64-65 (in Chinese with English abstract)

Gao XJ, Zhao ZC, Giorgi F (2002) Changes of extreme events in regional climate simulations over East Asia. Adv Atmos Sci 19:927-942

Hong Y, Adler RF (2008) Predicting global landslide spatiotemporal distribution: integrating landslide susceptibility zoning techniques and real-time satellite rainfall estimates. Int J Sediment Res 23:249-257

Kendall MG (1975) Rank-correlation measures. Charles Griffin, London, p 202

Liu GC (1995) Discussion on the effects of meteorological disasters on the national economy of Xinjiang. Arid Zone Res 12(03):7-14 (in Chinese with English abstract)

Liu L, Hong Y, Bednarczyk CN, Yong B, Shafer MA, Riley R, Hocker JE (2012) Hydro-climatological drought analyses and projections using meteorological and hydrological drought indices: a case study in Blue River Basin, Oklahoma. Water Resour Manag 26(10):2761-2779

Loukas A, Llasat MC, Ulbrich U (2010) "Extreme events induced by weather and climate change: evaluation, forecasting and proactive planning" Preface. Nat Hazards Earth Syst Sci 10(9):1895-1897

Mann HB (1945) Non-parametric tests against trend. Econometrica 13:245-259

Palmer WC (1965) Meteorological drought. Office of Climatology Research Paper 45, Weather Bureau, Washington, D.C, p 58

Peterson TC, Easterling DR, Karl TR, Groisman P, Nicholls N, Plummer N, Parker D (1998) Homogeneity adjustments of in situ atmospheric climate data: a review. Int J Climatol 18(13):1493-1517

Qiang ZA, Wu TW, Song MH, Ma XB, Cai Y, Liang XY (2001) Arid disaster and advances in arid climate researched over northwest China. Adv Earth Sci 6(01):28-38 (in Chinese with English abstract)

Qing DH (2008) China's major meteorological disasters and development trend. China Emerg Rescue 6:4-6 (in Chinese with English abstract)

Sen PK (1968) Estimates of the regression coefficient based on Kendall's Tau. J. Am. Stat. Assoc 63:1379-1389

Shi YF, Shen YP, Kang E, Li DL, Ding YJ, Zhang GW, Hu RJ (2007) Recent and future climate change in northwest china. Clim Change 80:379-39
Sun G, Chen Y, Li W, Pan C, Li J, Yang Y (2014) Intra-annual distribution and decadal change in extreme hydrological events in Xinjiang, Northwestern China. Nat Hazards 70(1):119-133

Wells N, Goddard S, Hayes MJ (2004) A self-calibrating Palmer Drought Severity Index. J Clim 17(12):2335-2351

Xu ZX, Chen YN, Li JY (2004) Impact of climate change on water resources in the Tarim River basin. Water Resour Manag 18:439-458

Xu GH, Mao WY, Lu GY (2008) Xinjiang meteorological weather changes and general statement on the work of disaster prevention and reduction. Desert Oasis Meteorol 2(01):50-54 (in Chinese with English abstract)

Ye MQ, Chen BH (1996) Research on natural disaster zoning in Xinjiang. J Nat Disasters 5(01):14-21 (in Chinese with English abstract)

Yue S, Pilon P, Phinney B, Cavadias G (2002) The influence of autocorrelation on the ability to detect trend in hydrological series. Hydrol Process 16(9):1807-1829

Zhang YC, He WX, Li SK (1991) Introduction to Chinese agricultural meteorological disasters [M]. China Meteorological Press, Beijing

\section{Submit your manuscript to a SpringerOpen ${ }^{\mathcal{D}}$ journal and benefit from:}

- Convenient online submission

- Rigorous peer review

- Immediate publication on acceptance

- Open access: articles freely available online

- High visibility within the field

- Retaining the copyright to your article

Submit your next manuscript at $>$ springeropen.com 